\title{
Translation Education in China in the Shifting Age
}

\author{
Weimin Yuan \\ Assumption University \\ Bangkok, Thailand \\ Foreign Trade and Business College \\ Chongqing Normal University \\ Chongqing, China
}

\begin{abstract}
This paper analyzes the changing world and its great influences over translation education in China with the very aim to explore the relation between academic education and the translation industry in a changing world, especially the essential corresponding changes in translation education in the changing age in Chinese educational setting, preparing real professional translation talents for translation market.
\end{abstract}

Keywords-the changing word; translation education in China; essential corresponding changes in translation education

\section{INTRODUCTION}

In the past years education of Translation in China has achieved great leaps at three crucial points: in 2004, $\mathrm{PhD}$ of Translation Studies; in 2006, BA degree of translation; in 2007, Master degree of Translation and Interpreting (Zhu, 2014). Another leap is followed by the formal acceptance as one member on the official list of majors in colleges and universities in China (Ping, 2014). Since the starting of BA degree of translation in mainland China, the number of universities or colleges with BA degree of translation jumps from 3 to 230. In 2014, the number of students majoring in translation rises up to 14693 (Shi, 2015). The progress of development of translation education is pushed greatly by the Belt and Road policy initiated by China in recent years. The news from Youth Daily Newspaper states that in 2017 many new majors of BA degree come into the official lists of colleges and universities, especially some new foreign languages such Uzbek, Czech, Polish, and Kazakh in Shanghai International Studies University. This is the proper response by universities to national strategy of our country. However, there appears a paradoxical situation. On the one hand, the developing translation market in China at high speed is facing with great shortage of translation talents; on the other hand, every year so many students majoring in translation cannot find a job to survive in society, still less the job corresponding to their majors. Naturally, translation education comes into spotlight in Chinese academia in recent years. Many Chinese scholars have made their creative contributions to it. This does great benefit to the development of Chinese translation education. Though almost each essay on Chinese translation education involves the background of Chinese education, still up to now, there is no detailed analysis of the change in the environment of Chinese translation education and its great influence on corresponding aspects of translation education. Thus this paper aims to explore the changing situation, internal and external, the big background of translation education research and its influence over Chinese translation education, bringing the sense of understanding the present Chinese translation education up to date.

\section{TRANSLATION EDUCATION IN THE CHANGING}

\section{A. Background}

1) Translation in the age of globalization and "internet plus": The world is changing more dramatically and rapidly than ever before, especially when it steps into the era of "Internet Plus", the pace of its globalization is increasingly accelerating at unprecedented speed. Translation itself also have gained great leap in the past years. Together with information and technology, translation changes in many aspects.

In nature, translation now goes beyond simply pure translation, orientating to translation service, especially added value service, shown in the following "Table I".

\begin{tabular}{|c|c|}
\hline TABLE I. & $\begin{array}{l}\text { LATION IN THE AGE OF GLOBALIZATION AND } \\
\text { "INTERNET PLUS" }\end{array}$ \\
\hline Text preparation & Technical writing \\
\hline ST/TT adjustment & $\begin{array}{l}\text { Pre-and post-editing } \\
\text { Transcription } \\
\text { Adaptation, rewriting } \\
\text { Updating } \\
\text { Internationalization } \\
\text { Localization, Globalization } \\
\text { Transliteration } \\
\text { Legalization, notarization } \\
\end{array}$ \\
\hline Quality control & Review and revisions from third parties \\
\hline Audiovisual & $\begin{array}{l}\text { Subtitling } \\
\text { Voice-over }\end{array}$ \\
\hline $\begin{array}{l}\text { Translation memories } \\
\text { and terminology work }\end{array}$ & $\begin{array}{l}\text { Translation memory alignment } \\
\text { Alignment of bilingual parallel texts } \\
\text { Terminology database creation and termbase } \\
\text { management } \\
\text { Terminology concordance }\end{array}$ \\
\hline Technical services & $\begin{array}{l}\text { DTP } \\
\text { Graphic design } \\
\text { Web design } \\
\text { Camera-ready artwork }\end{array}$ \\
\hline Consulting & $\begin{array}{l}\text { Language consultancy } \\
\text { Culture consultancy }\end{array}$ \\
\hline
\end{tabular}

a. (European Committee for Standardization 2006: 17). (Biel, 2011) 
It means the differences in the assignments given to translation agencies (and consequently their profits) will be determined not only by the quality of their translation products but also by the range of services they offer potential clients. Lionbridge has the largest disclosed revenues (\$489m in 2013), makes much of its money from services other than translation.

Furthermore, in nature, the function of translation has also changed a lot, from the means of transferring meaning from one language to another to the means of localization which is defined as "taking a product and making it linguistically and culturally appropriate for the target locale (country/region/language) where it will be used and sold" (emphasis intentional) (Esselink ,2000). Undoubtedly, translation has achieved the great status than ever before from passive to active functional role in localization.
Still, in nature, translation has also changed from the transference of meaning to translation writing or technology writing, even transcreation which is a term used chiefly by advertising and marketing professionals to refer to the process of adapting a message from one language to another, while maintaining its intent, style, tone and context.

In the working manner, translation has experienced a great leap from traditional workshop to team collaboration, even from team collaboration to crowdsourcing which is a translation model that reaches out to a large virtual crowd on the Internet to obtain translations (O'Hagan 2011). Outsourcing has already been the dominant operational model, shown like the following "Fig. 1".

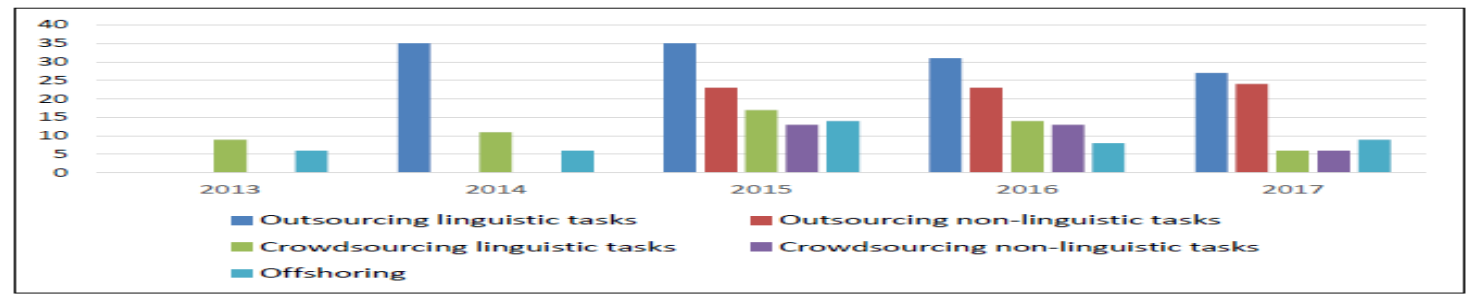

Fig. 1. Outsourcing.

Taking Windows Operating System as an example, its localization involves many languages as Windows 7 with 35 languages for SKU, 6o languages for system interface, 100 languages for internal resources; Windows8 with 109 languages for all resources. This great work cannot be done by translators alone. It needs a big working network, which is management system of project localization. (Wang, Leng \&Cui, 2013)

In the working content, translation has to face with unprecedented diversified texts from traditional texts to hybridization of text types and genres: multimodal texts, even super-text or hypertexts. Hypertexts are a kind of multilinear electronic texts, which contain at least two different types of sign elements connected by hyperlinks. Numerous hypertexts have formed the Internet, which has become the translator's new working environment in the digital age. This gave rise to other types of translation such as website translation, multimedia translation, software localization, mobile application translation, etc.

In the structure of translation talents, owing to the great change in translation, translation industry forms different specifications for translation talents, not simple or pure translator but versatile translation service provider. In their
Training the Language Services Provider for the New Millennium, Maia, Haller, and Ulrych (2002) stated that "Nowadays students need to be trained for the much wider variety of roles summed up in the phrase, 'language services provider' (MIZAB \&BAHLOUL, 2016). This involves many job positions such as an information management expert, technician, terminologist, phraseologist, translator, adapter, proof reader, reviser, quality control expert, post editor, editor, graphic design expert, web page designer, technical writer, website designer, web page integrator, file manager, macro-command writer IT specialist (2007, as cited in Sakwe, 2015). Nowadays, it is unthinkable to be a professional translator without having access to Translation Memories and desktop publishing software. Without these, there is no profit to be earned in translation work (Aula.int, 2005).

In the scale or turnover, the growth of the language services market is enormous: according to studies by the Common Sense Advisory (CSA), an independent consulting firm from Massachusetts specializing in language services, the global language service market had a value of USD 34.8 billion in 2013, almost 37.2 in 2014, and in 2015 it was USD 38.2 billion - resulting in an annual growth rate of $6.46 \%$, just like the "Fig. 2". 


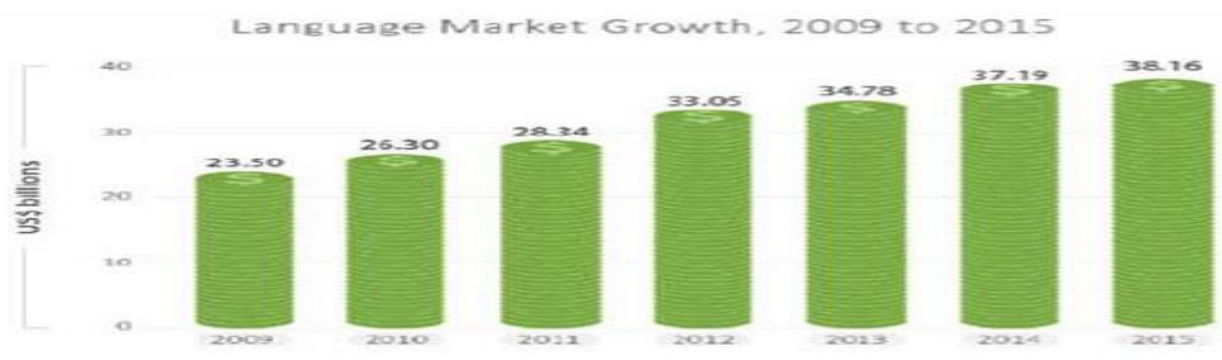

Fig. 2. Language Market Growth from 2009 to 2015 as reported by Common Sense Advisory (Steiert \& Steiert, 2016).

In 2015, the revenue was distributed as follows: Europe $53.09 \%$, North America $34.82 \%$ and Asia with $10.49 \%$. The anticipated global turnover for language services already stands at USD 49.8 billion for the year 2019. One fact is found that European and American accounts for a lion's share, dominating the market. Though Asia only seizes the smallest slice of language industry pie, it gains its significant ground, fueled largely by China.

From the analysis above, one fact is found that the changes in translation promote the reform of translation management, increasingly making translation service transform from manual workshop to industrialization of mass production typical of scale, procedure, coordination, and crowdsourcing. Modern information and technology, especial internet, radically subverts translation from the layers of model, standards, and scale, making it work as other fields in the orbit of modern industry with similar production system, greatly raising its efficiency, finally coming into being a large industry. Thus the nature of translation similar to other industries in the economic society forms the foundation of standardization of translation training in this study. This foundation requires dealing with training as working in other economic events with standardized procedure through the whole process.

\section{B. The Growing Translation Industry in China}

China as a new emerging market, according to the report from TAC (Translation Association of China), it was estimated that the revenue generated by language service sector amounting to $\$ 11$ billion in 2011. Though the concrete number is not clear, after six-year's growth, up to now, the market of language service in China is indisputably larger than ever before, greatly fueled by Chinese strong economic growth. Another data shows from 1980 to 2011, the number of enterprises of language service in China increased from 16 to 37197 , with an average of $30.3 \%$ per year, and it is estimated that it will increase to more than 60000. Up to now, the number of employees in this field has risen to 1190000 , not mention to say more than 3400000 part-time employees (Ge, 2012). The fast growth of translation industry is largely contributed by globalization and 'Internet Plus', and is now greatly promoted by the present Chinese national strategy of the Belt and Road, initiated by Chinese president Xi Jinping. The 'One Belt' part of it refers to the Silk Road Economic Belt while the 'One Road' refers to the 21st-century Maritime Silk Road, geographically shown in the following figure.

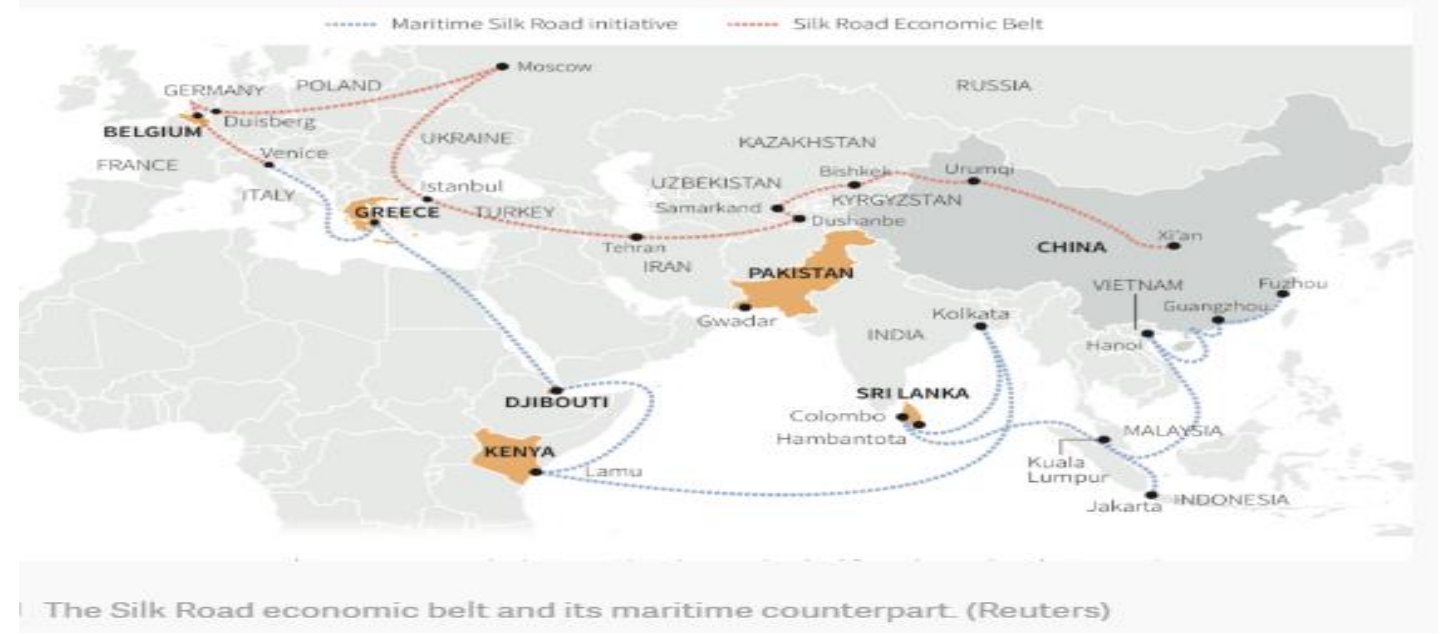

Fig. 3. The Silk Road economic belt and its maritime counterpart. (Reuters)

Jointly, they're meant to be a revival of the ancient Silk Road trading routes. The initiative covers a vast area of 53 countries with 94 cities involved, a population of 4.4 billion, and a national gross economy up to 21 trillion US dollars. The great project involves 50 universal languages and at least 200 important languages of minorities (Li, 2015). The grand diplomatic policy increasingly speeds up the further industrialization of translation in China, especially changing language combination of translation from universal languages to minority languages and enlarging translation 
scope, not only content but also strategic status of translation in the initiative. However, compared with European and American mature system of translation development, Chinese translation is still at the beginning stage transforming from traditional role to modern role, with many gaps to be filled in many aspects such as professional standards, technology, education, etc. It is obvious that in this field China still has a long way to cover, making translation keeping pace with its economic growth. Also, admittedly, the fact that the state of the lion's share of Chinese translation market taken by Europe and the Unites States cannot be changed in a short time. It involves many aspects, one of which is the lack of professional translators and related professionals familiar with this industry. This poses a great challenge for the further development of Chinese translation market. It is especially true because Chinese language service Industry is still at the very primary stage of industrialization (Du and Hua, 2016).

\section{Industrial Development and Reform of Higher Education in Chinese Mainland}

In the era of information age, information and technology gain their great momentum to speed up the development of industry. It leads to two changes: one is more and more emerging industries; the other is increasingly fine segment of labor. This poses a great challenge for human resources. Though China still keeps its strong growth rate, its momentum of growth slowdown. China now stays at a very crucial point, as experts say at the bottle-neck stage. Its economic development confronts with its inborn structural problem. One of the problems is the structural shortage of human resources. In the past decades, China forges its way to strong economic growth, based on lower cost of labor force, properly fit for the type of labor-intensive economy. But now with the coming of 'information age', labor-intensive development cannot meet today's situation. In order to meet with the situation, especially maximize the role of the driving force of socio-economic development of human resources, policy makers have come to realize the importance of investing in education and training as a way of improving the existing stock of skills. This places great emphasis on competence or skills. In this way stakeholders can prepare skills needed for the future, to realize a better matching between available skills and those required in the labor market, and to bridge the gap between the worlds of education and work. Universities are afforded a special role in bridging the gap between the worlds of education and work. However in China, long-time persistence of higher education lies in the education of academic talents. This is largely because of lack of enough awareness of the influence of the transformation of economic structure over education. The original orientation of educating elite for society is out of date. It has to give its way to the new orientation of educating skilled and technical labor force. In this context, higher education is far away from Chinese social reality. For translation in Chinese higher education, policy makers or experts persist in education-oriented instruction at undergraduate and training-based instruction at postgraduate level, as two sequential wholes. It means the education at undergraduate level belongs to academic education, caring little about students' professional training for forthcoming stepping into society. However, they overlook a fact that today's Chinese higher education is different from that in the past, also from that in other countries. According to the news from the Ministry of Education of the People's Republic of China, in this year (2017) the number of graduates amounts to 7.95 million, near to the half of the total capacity of new increasing employment, but employment positions available are far from the needs of the pool of labor force because of the downturn of economy in the world. The gap is too large to fill, no wondering that the number of students attending postgraduate admission test creates a historic record, breaking 2 million in this year. On the one hand, more and more students cannot find their jobs directly linked with their majors; on the other hand, proper employees in specific positions cannot be easily found by employers. The falling employment rate and the worsening situation of hiring employees present an ironical picture of embarrassment of Chinese higher education. In order to change the worsening situation, Ministry of Education of the People's Republic of China design to start the reform of transformation of the majority of colleges and university from academic-oriented education to professional-oriented education, with aim to educate technique-and-competence-oriented talents. In order to seek a new development and meet the trend of the reform of higher education in China, translation major has to walk its way to profession-oriented education, making students with the professional competence to survive in the real life. The very nature of translation is its practicality. It also requires developing the true or real professional competence or work-ready competence as the central job of education of translation program rather than academic achievements.

\section{THE CHANGE IN EDUCATION ORIENTATION FROM \\ ACADEMIC EDUCATION TO PROFESSIONAL EDUCATION}

Obviously, translation has developed into a huge industry with its own working law and standards, especially as a special service with its own practices and procedures. The change in nature of translation from simple translation to translation service asks the change from academic education to professional education. Thus it is obvious that the past translation education in China cannot follow the pace of the times. This gets more and more attentions from the academia in China. Some scholars propose professional translation education as a response to the changing translation market. $\mathrm{Mu}$ (2012) explored the difference between the past traditional translation education and professional translation education in teaching concept, teaching environment, teaching content, teaching materials and methods, teachers, and teaching management. The fact is also revealed by Yuan (2012). He states that in China the upgrading of translation into language service is in nature to be line with the international rules and practices of the translation industry in the world. Naturally this also asks the corresponding upgrading of Chinese translation education.

Specifically, this gets greatly involved with the construction of translation programme. The background of this study tells that in today's modern translation industry, translation has to be redefined as the translation service. The 
meaning of traditional 'translation' is only one part of the project cycle and requires team work and collaboration of the parties involved. Professional fields need the integration of many skills, not prescriptive knowledge or certificates and diploma of the representation of them. This view is in line with the idea of professional realism of training recommended recently in several approaches (Kiraly, 2005; Kelly, 2005; and Gouadec, 2007). However, translation programs cannot meet the standard. Thus Kobus Marais (2013) proposes to rethink the assessment for both industry and academy, reaching constructive alignment in translator education. The standard may serve as a guideline for training institutions with practically-oriented programs. It extends a broader view of translation as part of the translation service. This is the market expectation to train translation service providers rather than translators. Translation is very different from that in the past. Translators are also different now. The training of translators naturally goes as translation industry does. Putting professional standards as the minimum requirements must be the only choice left for training institutions if they want to ensure market-oriented training. It means that the translation programs or majors in China have to change their orientation from knowledge-oriented talents to competence-oriented talents. This change is also required by translation per se. Its strong practicality makes itself very different from other subjects of arts. The practicality is greatly influenced by the change of the times, making translation industry greatly different in scale, nature, working manner, working content, and the structure of translation talents. This difference made by market requires different training or education for different talents to meet with the needs of industry and economy. This requires the change of education from pure translation knowledge to professional competence. This means the reform of the orientation and the structure of present translation program is essential and urgent in present situation. Conceptually this needs to tell the difference of two couple terms often discussed in the translation academia. One is the difference between translation programme and foreign language programme. Translation as a discipline originates from foreign language programm. It is very necessary to get away from the confinement of foreign language programme in the theoretic categories, disciplinary system, training objectives, teaching standards, curricular structure, and evaluating system for talents (Lan, 2015). The other one is the difference between teaching translation and translation teaching. This is a longtime heated topic in the academia. Delisle (1998) first proposed the two terms. Mu (2008) made clear difference between the two terms in disciplinary orientation, teaching aim, teaching points, and training objectives. Interestingly, up to recent years, the two terms are still in discussion in the academia (Lai, 2013; Wang, 2014; Mo\&Xie, 2014). It shows that though academia has reached an agreement on the understanding the difference of the two terms, the difference of two terms are still in reality crucial to the construction of translation programme and translation teaching. Specifically, Standards for translation programme is urgently needed to be established (Lan, 2014). This is a real move to make the distinction from foreign language programme, being in line with translation industry. The detailed analysis is shown as the followings.

\section{A. The Change in Talent Orientation from Pure Translator to Translation Service Provider}

With translation as professional service, the past talent orientation is still out of date. In a modern translation industry, different types of talents are needed not only translator. This means translation programmes should be oriented at training translation service providers rather than translators. Students have to be trained as versatile roles: translator, reviser, reviewer, proofreader, project manager, DTP publisher, or graphic designer (Biel, 2011). The orientation for multiple roles, on the one hand, represents the market need; on the other hand, students can get ready for future career with great freedom and interest to make their own choice as different roles not confined to translator. The versatile quality of the orientation will facilitate the development of student's real professional competence. This professional competence is a comprehensive transverse. It requires corresponding competence-based education in translation education instead of the past knowledge-based education.

\section{B. The Change in Teaching Content}

From the previous analysis, one fact is found that in nature the function of translation has changed from literal translation to localization. It means translation goes beyond the past expectation from passive role as language aid to active participant in translation industry, even in language industry. In this sense, translation industry and language industry need very different special skills, to great extent; these skills can be called expertise. These types of skills cannot be provided by the traditional education. This suggests that translation skills or translation competence cannot meet the requirements of the market or industry. Students majoring in translation have to master translation skills, the technology of localization including transcreation. More importantly, students have to change their idea from traditional role as translator into language service providers for localization. So to speak, it is a subversion of the traditional teaching content. This also poses a great challenge for the present translation education. This is required by professional education with the aim to develop student's translator' competence (Kiraly, 2000) or literacy (Li, 2014).

\section{The Change in Teaching Materials}

Owing to the diversity of texts dealt with in modern translation, the teaching materials have to be changed from the traditional literature texts to different types of pragmatic texts, even super-texts, popular in the present society. The definition of text has been extended beyond the limit of traditional translator owing to the fast development of modern information technology, especially in the age of "Internet Plus". In other words, the modern translation is more specialized and more detailedly divided. Translation market or industry requires experts at not only translation but also specific fields. Ironically, even in today's translation education, whether students have acquired translation 
competence is still a question, let alone translator competence or expertise at special fields. This actually poses a challenge about how to intertwine the different types of text into teaching content. It means students majoring translation have to be familiar with different types of texts at the level of technicality and content or subject matter. Thus translation is really developed into a complicated technology in the context of localization. This type of technicality is the striking feature of modern translation. It forces translation education to reform the teaching content so as to cater for the market needs. Typically, in the translation education, authentic texts from professional life have to be attached great importance. On the one hand, these texts come from life, greatly arousing student's interest; on the other hand, these texts will be met in student's future career, creating a simulating environment of professional work, narrowing down the gap between academic education and professional fields. In this way, students can transit from student identity to para-professionals gradually. Admittedly, introduction of modern translation texts into contemporary classroom needs a gradual process. More importantly, it needs a careful scheme with great focus on the structuring of the proportion of traditional texts to modern texts as well as the concrete time point and time allocation, not aiming to simply use one to replace the other. All needs to be done completely in line with the smooth interaction between translation education and translation industry with all stakeholders participating into the construction of ecosystem of translation education, especially into the construction of translation programmes. This involves more or less every aspect of the construction of translation programmes. The revolutionary recreation of translation programme, even the importance for translation industry in China, is totally self-evident.

\section{The Change in Teaching Mode}

Thanks to the modern information technology, especially in a special age of "Internet Plus", the working manner of present translation industry has greatly changed from separate workshop to team collaboration, even to crowdsourcing. The traditional translation manner often with one or several translators cannot agree with the total atmosphere in the present translation industry. In this industry, huge information needs to be widespread within a very short time in the different types of languages. This is out of traditional translating manner. Obviously, this is also the typical representation of modern industry including translation. Translation education has to follow the manner of translation industry. The following aspects should be attached more importance to.

1) The change from teacher-centered to studentcentered: Kiraly (2000) innovatively introduced social constructivism into translation education. He proposed the important concept of transformation from teacher-centered transmission to learner-centered learning. This means a shift from the transmission of knowledge by teacher to active construction by student's participation. From the angle of modern translation industry, especially the change in the working manner, the term of student-centered here needs to be further explored. Student-centered had better be replaced as students-centered. This change in concept intends to put one student in a small team or a big environment. This can remove the mistaking of student-centered as individualism or separation. This puts student's behavior under the framework of collective principles of an organization or one industry. It is a way to highlight the importance of social identity for student's growth. Social constructivism makes itself different from other constructivism in "social". One student can empower himself or herself through social communications in a social team or group. They, serving as different roles in the social team or group, facilitate the interaction or communication among all team members, maximizing the power of the team or the group. In this sense, teacher is not absent. He or she as the scaffold can not only help student as individual grow up but also help students as a team grow up. This can be a good cure for the ineffectiveness of the present training. In the training, students often work mechanically and individually only with the collaboration on the surface, lacking of chemical reaction among members. To some extent, they only finish the task as the schedule or procedure required. The real core qualities such as interpersonal skill, mutual trust, responsibility, the sense of collective honor, etc. cannot be found improved a lot. These qualities are crucial or essential elements for a successful professional translation service provider. This also reflects the nature of translation as an industry, in which collective collaboration and integration are needed as the essential for mass production.

2) The change from product-oriented to processoriented: As an active response to the change from teachercentered to student-centered, teaching has to change from product-centered to process-centered. As Massey(2005) said: "if we accept that translation competence and its acquisition are dynamic processes, then the training of translators must necessarily be process-oriented and focus in large part on the development of procedural knowledge and procedural competence ". (Gary Massey, 2005)

From Massey's words, one fact can be found that process-oriented is attached great importance to translator training. The development of procedural knowledge and procedure competence plays a key role in the acquisition of translator competence. In today's translation education, processed-oriented teaching is the echo of Kiraly's social constructivist translator education theoretically; it also caters for the need of translation industry in reality. The present translation industry lays increasing emphasis on procedural competence. Furthermore, this tendency will continue to be strengthened with the gradual standardization of translation industry. It finally leads to the great improvement in the productivity of translation industry. Naturally, procedural knowledge has to be introduced into teaching content of translation education. Then through continuous practice (Kiraly, 2000), procedural knowledge will develop into procedural competence, the very core part of translator competence. 
3) The change from classroom to professional field: As suggested by social constructivism, knowledge is the internalization of social activity (Vygotsky, 1978). This can be shown in Kiraly's statement.

Essential features of social-constructivist educational experiences will include authentic practice in actual professional activities, a collaborative learning environment including not only interaction among students but also the extensive involvement of the students in every aspect of the teaching/learning process, including syllabus and curriculum design, task selection, sub-task identification and assessment of their own performance and learning, as well as program effectiveness (Kiraly 2000: 17) 'social activity', 'authentic practice', 'professional activities', 'learning environment' are key words the citations above. These words points to the educating environment for translator education. In this environment students can interact with all elements of it and construct knowledge by experiencing not by study in the form of transmission. Obviously, the authenticity of the environment is crucial. It matters with whether students can acquire the real translation competence in the end. This poses a challenge for creating a similar or simulating environment. The task cannot be easily by education institutes. It needs the interaction among all stakeholders involved, especially the close link between translation industry and education institutes. The gap between education institutes and translation industry can be dealt with the following trials: introducing professional industry into educational setting, taking translation programme out into translation industry, and building the experimental base for apprenticeship as the bridge over the gap, not only as a place for students to practice and train, but a place with the function of preparing students' transition from student identity to para-professional identity. To some extent, majority of today's experimental base cannot serve as expected like this. In addition, the shortening of the gap between education institutes and translation industry has to be reasonably allocated into different stages in a normal educating system, not confined only in senior grade, even in the very end of graduation in the form of graduation internship. The familiarity with professional environment is the typical representation of a mature professional, full of confidence, professional sensitivity, and professional wisdom.

\section{E. The Change in Educating System}

In order to follow the pace of translation industry, Chinese educating system is also needed to change. This is very true for translation education. After translation achieved its official status as an independent discipline, translation educating system is basically built. It has clear-cut three levels: bachelor, master, and Doctor. According to this system, translation bachelor aims to educate general translation talents. Master is classified into two types: academic talents and professional talents. Doctor degree is aimed for academicians. However, this system has to face the very embarrassing situation: on the one hand, translation industry lacks special translation talents; on the other hand, students majoring in translation cannot find jobs matching with their expertise. The majority of students majoring in translation are only at the level of bachelor degree, not master degree because only a small part of students have a chance to further study at the level of master degree. This is not fit for the present reality in China. The great majority of students at the level of bachelor cannot easily find a job related to their major, even in unemployment. For the master degree, especially for professional master degree, the situation is not also good, only small part of students enter into professional career as expected. There must be something wrong with the design of the educating system. One is how to match the education at the level of bachelor degree with the education at the level of master degree. It means professional education cannot be only placed at the level of master of translation and interpreting oriented for profession. In the education at the level of bachelor, there is still the need to integrate professional education through all stages. If the design can be changed in this way, at least students with bachelor degree can find jobs matching with their major, living through the impasse of employment. Meanwhile, professional education can streamline the whole translation education from bachelor to master, forming a complete mechanism or system to empower students for future professional career. For the majority of colleges and universities in China this is also an active response to the requirement of transformation from academic-oriented education to applied-oriented education by the Ministry of Education of China.

\section{CONCLUSION}

The world is increasingly changing. Translation industry in the world is also accelerated with the combination of globalization and "Internet Plus". Chinese translation industry has inevitably to follow the pace of the times. In such a big context, Chinese translation education must be greatly influenced, involving education orientation, talent orientation, teaching content, teaching materials, teaching mode, and educating system. To some extent, translation education has to be transformed, even reconstructed, not only responding to the changes internal and external, but also forming a mechanism sensitive to these changes. It must be a tough job. It is actually of great importance and value for translation education as well as for translation industry.

\section{REFERENCES}

[1] Aula.int. (2005). Translator training and modern market demands. Perspectives: Studies in Translatology, 13(2), 132-142.

[2] Esselink, B (2000) A Practical Guide to Localization, Amsterdam and Philadelphia: John Benjamins Publishing Company.

[3] Gary Massey. (2005). Process-Oriented Translator Training and the Challenge for E-Learning. Meta, 50(2), 626-633.

[4] Ge, X. (2012). Speeding up the Development of Translation and Serving Overall Situation of the Communication between China and Abroad. Retrieved from http://news.163.com/12/1206/10/8I1L1HKC00014JB6_all.html

[5] Gouadec, D. (2007). Translation as a Profession (Vol. 73). Amsterdam: John Benjamins Publishing Company. https://doi.org/10.1075/btl.73

[6] Hua, Z., \& Du, K. (2016). Language Service Market and Translation Education in the Age of Internet ---The Review of the Seven Session of the Communication Congress of Chinese Professional Translation. 
Retrieved

from http://blog.sina.com.cn/s/blog_d71758400102w7xi.html

[7] Lan, H. (2015). Translation Teaching---The Key of the Development of Translation Studies as Independent Discipline. China University Teaching, (6), 32-37.

[8] Li, R. L. (2011). Redefining the Goal of Translator Education: A Shift from Translation Competence to Literacy Development. Chinese Translators Journal, (1), 165-166.

[9] Kelly, D. (2005). A handbook for translator trainers: a guide to reflective practice.

[10] Kiraly, D. C. (2000). A social constructivist approach to translator education : empowerment from theory to practice. St. Jerome Pub.

[11] Kiraly, D. (2005). Project-Based Learning: A Case for Situated Translation, 50, 1098-1111.

[12] Maia, Belinda, Johann Haller, and Margherita Ulrych (eds). Training the Language Service Provider for the New Millennium. Porto: Faculdade de Letras da Universidade do Porto.

[13] Mizab, M., \& Bahloul, A. (2016). The Integration of Professional Translators' 21 st Century Profile in Teaching Translation at Batna University, (3), 187-209.

[14] Mo, X., \& Xie, W. (2014). From Teaching Translation to Translation Teaching: An Approach to Innovation in Chinese-French Translation Teaching, (1), 77-81.

[15] Mu, L. (2012). Professionalization of Translation and the Education of Professional Translation. Chinese Translators Journal, (4), 13-14.

[16] O'Hagan, M. (2011). Community translation: Translation as a social activity and its possible consequences in the advent of Web 2.0 and beyond. Linguistica Antverpensia, 10, 11-23.

[17] Ping, H. (2014). The Interpretation of Teaching Requirements of BA of Translation. Chinese Translators Journal, (1), 53-58.

[18] Lai, R. (2013). On Education of Translation Talents in Colleges and Universities from the Point of View of Teaching Translation and Translation Teaching. Journal of Hubei University of Economics (Humanities and Social Science), 10(11), 117-118.

[19] Shi, Y. (2015). The Education of Translation Talents and the Reform of Translation Teaching under the Environment of the Grand Diplomacy. In The Joint Conference of English Teachers in Beijing Region.

[20] Steiert, Y., \& Steiert, A. (2016). Translation in transition: A comparison of Western and Chinese language markets China emerges.

[21] Vygotsky, Lev S. 1978. Mind in Society: The Development of Higher Mental Processes. Cambridge, MA: Harvard University Press.

[22] Wang, H., Leng, B., \& Cui, Q. (2013). Restudy Applied Translation System in Information Age. Shanghai Journal of Translators, (1), 713

[23] Wang, W. (2014). The Construction of Translation Programme of BTI : State Quo, Problems, and Solutions, 27(5), 173-175.

[24] Yuan, J. (2012). Language Service---The Brand-new Orientation of Chinese Translation Industry. The Chinese Translators, (5), 1-4.

[25] Zhu, C. (2014). Development of Translation Education in Chongqing: Status Quo, Problems and Solutions. Foreign Language and Literature, 30(1), 106-111. 